\title{
ANÁLISE DA UTILIZAÇÃO DA POSSE DE BOLA DURANTE O PROCESSO OFENSIVO NO FUTSAL CONTRIBUTO PARA A DETERMINAC̣ÃO DA EFICIÊNCIA COLECTIVA
}

\author{
ANALYZE OF THE BALL POSSESSION DURING \\ THE OFFENSIVE PROCESS IN INDOOR SOCCER \\ CONTRIBUTE TO DETERMINE THE COLLECTIVE EFFICIENCY
}

\author{
AUTORES \\ Ricardo Duarte ${ }^{1}$ \\ ${ }^{1}$ Universidade de Évora
}

ANÁLISE DA UTILIZAÇÃO DA POSSE DE BOLA DURANTE O PROCESSO OFENSIVO NO FUTSAL 4(2): 77-82

\section{PALAVRAS-CHAVE}

posse de bola; finalização; eficiência colectiva.

\section{KEYWORDS}

ball possession; finalization; collective efficiency.

\section{RESUMO}

0 presente estudo tem por objectivo criar um conjunto de indicadores que permita analisar a utilização da PB no ataque, nomeadamente através da caracterização da primeira e da última acção, do número de passes e do tempo de Posse de Bola Com Finalização e de Posse de Bola Sem Finalização, do número total de remates, do número de remates enquadrados e dos golos. Partindo destes indicadores, propomos a utilização do Coeficiente de Produção Ofensiva e do Coeficiente de Eficiência da Finalização, como medidas que permitem aferir sobre a eficiência colectiva no futsal.

Para tal utilizamos como amostra a primeira parte da final do Campeonato do Mundo China-Taipé, disputada entre a Espanha e a Itália.

De acordo com os coeficientes referidos, a Itália estará a ser a equipa mais eficiente no jogo, uma vez que conseguiu criar uma percentagem de situações de finalização mais elevada e tem maior percentagem de remates enquadrados que 0 adversário. Apesar do resultado final estar sempre condicionado pela eficácia da finalização das equipas, parece-nos pertinente a utilização destes coeficientes, com vista à compreensão dos processos de jogo da equipa. $O$ futuro poderá passar pela disponibilização destes dados ao treinador durante $o$ jogo.

\section{ABSTRACT}

The aim of this study has create a joint of parameters to analyze the ball possession in attack, characterizing the first and the last action, the number of passes and the time of ball possession with finalization or non finalization, the total number of shoots, the number of shoots on goal and the goals. Starting by these parameters, we propose the utilization of Offensive Coefficient Production (CPO) and the Finalization Coefficient Efficiency (CEF), to measure the collective efficiency in indoor soccer.

So that, we were utilize the first time of the final world championship at China-Taipei, disputed between Spain and Italy, by the sample.

In according with the refers coefficients, Italy is the more efficient team in the match, given that it makes a more elevated percentage of situations with finalization and has more percentage of shoots on goal, that the opposite. The final score is conditioned by the efficacy of team finalization, but we think to be pertinent utilization coefficients, with view to comprehension the team processes in the match. The future goes by the coach access to this information during the game. 


\section{INTRODUC̣̃̃O}

O conhecimento científico sobre o Futsal tem aumento consideravelmente nos últimos anos. Contudo, devido à sua recente eclosão, muito há ainda a investigar nos mais diversos domínios. Relativamente à análise do jogo começam a existir alguns trabalhos de referência. Destacam-se os trabalhos sobre o perfil de actividade do jovem jogador ${ }^{5}$, a caracterização das fases ofensivas e defensivas das equipas $^{1,4}$ e a caracterização do esforço no treino e no jogo ${ }^{2,6}$. No entanto, o actual estado do conhecimento está ainda muito longe de outras modalidades.

Relativamente às estatísticas de jogo, a informação existente é recoIhida mediante critérios muito pouco claros, que encerram questões de validade não controlada. Apesar do seu uso se ter estendido, nos últimos anos, por várias equipas técnicas e observadores, as análises têm sido realizadas, essencialmente, através do registo de frequências de acções técnico-tácticas individuais, muitas vezes sem um problema objectivamente definido ao qual devem responder. 0 facto desta informação constituir material disperso e retalhado diminui a eficácia dos sistemas de observação ${ }^{3}$. Relativamente a indicadores colectivos que permitam aferir de alguma forma a eficiência dos processos ofensivos e defensivos, não existem estudos publicados no âmbito do futsal que indiquem um caminho. Contudo, os trabalhos existentes na área do basquetebol, originalmente emergentes dos conhecimentos existentes no Basebol ${ }^{8}$, poderão contribuir para a sistematização de alguns indicadores de eficácia colectiva no futsal. A eficácia colectiva em situação de jogo é habitualmente expressa pela eficácia ofensiva e defensiva. A eficácia ofensiva associa-se à capacidade das equipas converterem pontos, enquanto que a eficácia defensiva associa-se à capacidade das equipas impedirem a conversão de pontos dos seus adversários ${ }^{6}$. No futsal, a relação estabelecida entre Posses de Bola (PB) e finalização não tem o mesmo significado do basquetebol. Enquanto no basquetebol a PB termina frequentemente com finalização (lançamento ao cesto), no futsal existe um elevado número de PB sem finalização. Assim, a expressão da eficácia colectiva, através da relação entre o número de golos e o número de ataques, comparativamente ao basquetebol, não assume a mesma importância na análise do jogo de futsal.

Desta forma, sugerimos o conceito de eficiência colectiva, uma vez que nos parece poder ajudar a caracterizar os processos ofensivo e defensivo das equipas e ser mensurado como indicador de uma tendência processual do jogo no futsal. A eficiência colectiva pode ser definida como a relação entre as tentativas/possibilidades de finalização e a finalização em si.

Assim, o presente estudo tem por objectivo criar um conjunto de indicadores que permita analisar a utilização da PB no ataque, nomeadamente através da caracterização da primeira e da última acção, do número de passes e do tempo de Posse de Bola Com Finalização (PBCF) e de Posse de Bola Sem Finalização (PBSF), do número total de remates, do número de remates enquadrados e dos golos.

Pretendemos também propor 2 relações que permitam aferir sobre a eficiência dos processos ofensivo e defensivo no futsal, o Coeficiente de Produção Ofensiva (CPO) e o
Coeficiente de Eficiência da Finalização (CEF). O CPO exprime a relação entre as PBCF e o número total de PB, enquanto o CEF exprime a relação entre os Remates Enquadrados (RE) e as PBCF.

$[\mathrm{CPO}=\mathrm{PBCF} /(\mathrm{PBCF}+\mathrm{PBSF}]$ * 100 $]$
$[\mathrm{CEF}=\mathrm{RE} / \mathrm{PBCB}$ * 100 $]$

FIGURA 1

Equações do Coeficiente de Produção Ofensiva e do Coeficiente de Eficiência da Finalização.

De forma a poderem ser utilizados os dados para posteriores estudos longitudinais, os coeficientes propostos serão apresentados em percentagem (multiplicados por 100).

\section{METODOLOGIA}

\section{Amostra}

A amostra utilizada consiste na primeira parte da final do Campeonato do Mundo China-Taipé, disputada entre a Espanha e a Itália em 2004.

\section{Procedimentos}

Foi utilizada uma gravação vídeo do jogo, sendo efectuada a observação e registo numa ficha construída para o efeito. Posteriormente, o tratamento dos dados foi realizado no Microsoft Excel 2003.

A contagem do tempo foi feita a partir da cronometragem da realização. Devido a ter sido utilizada a gravação de uma transmissão televisiva, não foi possível identificar correctamente 4 sequências ofensivas, pelo que foram eliminadas da amostragem. 


\section{Definição dos parâmetros}

De forma a aumentar a fiabilidade da observação, definimos de seguida os conceitos que sustentam esta investigação.

\section{Posse de bola [PB]}

Controlo técnico-táctico ininterrupto e completo da bola. Para que se considere que a PB muda de equipa é necessário que a equipa que a recuperou execute 1 passe, 1 remate ou detenha o seu controlo durante 2 segundos. Desta forma, todas as jogadas de ataque que digam respeito à continuação da sequência ofensiva anterior, devido a uma intercepção ou desarme do adversário, são consideradas como o prolongamento da PB anterior.

Posse de bola com finalização (PBCF) Todas as PB que terminam ou contêm acções de finalização, ou seja, acções de remate e outras desenvolvidas com a intenção imediata de fazer golo.

Posse de bola sem finalização (PBSF) Todas as PB que não terminam ou contêm acções de finalização.

\section{Primeira acção da posse de bola (1APB]}

Primeira acção técnico-táctica desenvolvida pela equipa que recupera a PB. Essa acção pode ser:

Desarme - Acção técnico-táctica individual de natureza defensiva que permite recuperar activamente a bola que está sob o controlo de um adversário;

INTERCEPC̣̃̃o - Acção técnico-táctica individual de natureza defensiva em que, através da interposição de um segmento corporal sobre uma trajectória de passe, se recupera a $\mathrm{PB}$;

Defesa do guarda-Redes - Acção técnico-táctica individual que pretende evitar o golo da equipa adversária e através da qual se pode recuperar a $\mathrm{PB}$;
Reposição lateral - Acção técnico-táctica individual de natureza regulamentar através da qual se reinicia o jogo, após a bola ter saído pela linha lateral tocada em último lugar por um jogador da equipa adversária;

LANÇAMENTO DE BALIZA - Acção técnico-táctica individual de natureza regulamentar que permite repor em jogo, a bola que foi tocada em último lugar por um jogador da equipa adversária pela linha final ofensiva;

CANTo - Acção técnico-táctica individual de natureza regulamentar que permite repor em jogo, a bola que foi tocada em último lugar por um jogador da equipa adversária pela sua linha final defensiva; LIVRE - Acção técnico-táctica individual de natureza regulamentar que permite reiniciar o jogo após a equipa adversária ter cometido uma falta.

Última acção da posse de bola (UAPB] Última acção técnico-táctica desenvolvida pela equipa em PB. Essa acção pode ser:

PeRdA de BOLA - Acção resultante de um desarme efectuado por um jogador da equipa adversária;

PAsse interceptado - Acção técnico-táctica de passe que foi interceptado por um jogador da equipa adversária;

PAsse para fora - Acção técnicotáctica de passe mal direccionada que acaba por sair do terreno de jogo;

REMATE - Acção técnico-táctica individual de natureza ofensiva que visa obter golo de forma imediata;

MAu controlo - Acção que culmina da perda da $\mathrm{PB}$, resultante de um mau domínio da bola, sem oposição do adversário.

\section{Número de passes da posse de bola}

Número de passes efectuados pela equipa em PB.

\section{Número de remates falhados}

Número de remates que não são defendidos pelo guarda-redes, nem atingem a baliza, inclusive a trave e os postes.

Número de remates enquadrados Número de remates defendidos pelo guarda-redes ou que atingem a baliza, inclusive a trave e os postes, e os golos.

\section{Golos}

Número de remates que terminam em golo.

\section{Estatística}

Foi utilizada a estatística descritiva para tratamento dos resultados. Os dados foram recolhidos e posteriormente tratados no Microsoft Excel 2000.

\section{RESULTADOS}

De seguida apresentamos os principais resultados obtidos.

No quadro 1 podemos verificar um maior tempo de PB com e sem finalização da selecção da Espanha, contudo a Itália possui maior número de PBCF.

Pela observação do quadro 2 verifica-se que a Espanha utilizou maior número de passes, quer em situações de finalização, quer em situações sem finalização. Ambas as equipas utilizam em média menor número de passes em situações de finalização do que em situações sem finalização.

A acção mais utilizada pela Espanha para iniciar o seu ataque foi a reposição lateral, enquanto a Itália utilizou mais a intercepção para iniciar as PBSF e o desarme para iniciar as PBCF. 


\begin{tabular}{lcccccc}
\hline & \multicolumn{2}{c}{ PBSF } & & \multicolumn{2}{c}{ PBCF } \\
\cline { 2 - 3 } \cline { 6 - 7 } & Espanha & Itália & & Espanha & Itália \\
\hline Frequência & 26 & 22 & & 11 & 14 \\
Tempo & $496 \mathrm{~s}$ & $438 \mathrm{~s}$ & & $282 \mathrm{~s}$ & $153 \mathrm{~s}$ \\
Percentagem & $42,4 \%$ & $20,4 \%$ & & $24,1 \%$ & $13,1 \%$ \\
\hline
\end{tabular}

QUADRO1

Relação entre as Posses de Bola Com e Sem Finalização.

\begin{tabular}{ccccccc} 
& \multicolumn{2}{c}{ PBSF } & & \multicolumn{2}{c}{ PBCF } \\
\cline { 2 - 3 } \cline { 6 - 7 } & Espanha & Itália & & Espanha & Itália \\
\hline No passes & 173 & 76 & & 98 & 41 \\
\hline
\end{tabular}

QUADRO2

Relação entre o número de passes e a Posse de Bola Com e Sem Finalização.

\begin{tabular}{lrrrrr}
\hline & \multicolumn{3}{c}{ PBSF } & & \multicolumn{2}{c}{ PBCF } \\
\cline { 2 - 3 } \cline { 5 - 6 } & Espanha & Itália & & Espanha & Itália \\
\hline Desarme & $15,9 \%$ & $14,3 \%$ & & $9,1 \%$ & $42,9 \%$ \\
Intercepção & $15,4 \%$ & $33,3 \%$ & & $18,2 \%$ & $28,6 \%$ \\
Defesa Gr & $11,5 \%$ & $0,0 \%$ & & $9,1 \%$ & $0,0 \%$ \\
Reposição lateral & $35,0 \%$ & $24,0 \%$ & & $36,4 \%$ & $14,3 \%$ \\
Lançamento baliza & $23,1 \%$ & $19,1 \%$ & & $18,2 \%$ & $14,3 \%$ \\
Livre & $0,0 \%$ & $4,8 \%$ & & $0,0 \%$ & $0,0 \%$ \\
Canto & $0,0 \%$ & $4,8 \%$ & & $9,1 \%$ & $0,0 \%$ \\
\hline
\end{tabular}

\section{QUADRO3}

Caracterização da Primeira Acção da Posse de Bola Com e Sem Finalização.

\begin{tabular}{lrrrrr} 
& \multicolumn{2}{c}{ PBSF } & & \multicolumn{2}{c}{ PBCF } \\
\cline { 2 - 3 } \cline { 6 - 6 } & Espanha & Itália & & Espanha & Itália \\
\hline Perda de bola & $34,6 \%$ & $28,6 \%$ & & $0,0 \%$ & $0,0 \%$ \\
Passe interceptado & $38,5 \%$ & $19,1 \%$ & & $18,2 \%$ & $0,0 \%$ \\
Passe para fora & $26,9 \%$ & $38,1 \%$ & & $9,1 \%$ & $14,3 \%$ \\
Remate & $0,0 \%$ & $0,0 \%$ & & $72,7 \%$ & $78,6 \%$ \\
Mau controlo & $0,0 \%$ & $14,3 \%$ & & $0,0 \%$ & $7,1 \%$ \\
\hline
\end{tabular}

\section{QUADRO4}

Caracterização da Última Acção da Posse de Bola Com e Sem Finalização.

\begin{tabular}{|c|c|c|c|c|c|}
\hline \multicolumn{2}{|c|}{ Total remates } & \multicolumn{2}{|c|}{ Remates falhados } & \multicolumn{2}{|c|}{ Remates enquadrados } \\
\hline Espanha & Itália & Espanha & Itália & Espanha & Itália \\
\hline 17 & 17 & 11 & 7 & 6 & 10 \\
\hline
\end{tabular}

\section{QUADRO5}

Relação entre o número de passes e a Posse de Bola Com e Sem Finalização.
A última acção mais recorrente nas PBSF da Espanha é o passe interceptado, enquanto na equipa Italiana é o passe para fora. Nas PBCF ambas as equipas terminam maioritariamente com remate.

No quadro 5 verifica-se que apesar das duas equipas apresentarem o mesmo número total de remates, a Itália tem maior número de remates enquadrados.

\section{DISCUSSÃO}

\section{Utilização da Posse de Bola}

Relativamente às diferenças no tempo de PB entre as duas equipas, podemos referir que a selecção Espanhola teve $66,6 \%$ do tempo de PB total contra $33,4 \%$ da selecção Italiana. Contudo, devido à Itália ter registado maior número de $\mathrm{PBCF}$, podemos concluir que o tempo de duração das PB pode não ser um indicador preciso da utilização da PB. Apenas permite concluir que uma equipa privilegia um método de ataque mais rápido e objectivo (Itália) do que a outra (Espanha). Este facto é comprovado se tivermos em atenção o número de passes efectuado por cada uma das equipas. A Itália utiliza sempre um menor número de passes, quer nas PBSF, quer nas PBCF.

Para além do tempo e do número de passes, pode ser relacionada a quantidade de PB com e sem finalização. Para tal propomos o Coeficiente de Produção Ofensiva (CPO) como medida da percentagem de PB que atingem a fase fundamental de finalização:

[CPO = PBCF / [PBCF + PBSF $)$ * 100]

Assim, para a selecção Espanhola temos, CPO = 11 / (11 + 26) * 100 = 29,7\%; para a selecção Italiana temos, CPO = $14 /(14+22)$ * 100 $=38,9 \%$. 
De acordo com o CPO, a selecção Italiana estará a ser mais eficiente no jogo, ou seja, está a conseguir criar uma percentagem de situacões de finalização mais elevada do que o adversário.

\section{Acções determinantes na transição da Posse de Bola}

Depois de analisadas a primeira e a última acção de cada PBSF verificamos que a selecção Espanhola inicia 35\% dos seus ataques sem finalização através de reposições laterais, uma vez que a última acção mais frequentemente realizada pela Itália é o passe para fora $(38,1 \%$ ). Podemos concluir que o início do ataque através da reposição lateral poderá ser um aspecto importante na organização de jogo da selecção Espanhola, pelo que o treino destas situações estratégicas deveria ser reforçado. Por outro lado, a grande percentagem de passes para fora $[38,1 \%] \mathrm{da}$ selecção Italiana, comparativamente à menor percentagem de perdas de bola por desarme $[28,6 \%$ ] e passes interceptados $(19,1 \%)$, pode ser indicador de grande pressão defensiva do adversário, à qual os jogadores Italianos reagem com segurança optando preferencialmente por colocar a bola em zonas laterais que assegurem o equilíbrio defensivo em caso de perda de bola. Por seu lado, a selecção Italiana iniciou $33,3 \%$ dos seus ataques sem finalização através de intercepções de bola. A Espanha terminou 38,5\% das suas PB sem finalização com passes interceptados. Podemos concluir que, comparativamente à Itália, a Espanha aposta mais num jogo de passe para tentar aproximar o centro do jogo da zona de finalização, contudo, devido à qualidade defensiva adversária, existe uma grande percentagem de passes interceptados. Tal facto revela uma boa concentração colectiva e grande capacidade de antecipação dos jogadores Italianos, assim como uma boa transição ataque/defesa da selecção Espanhola, uma vez que o equilíbrio do jogo ainda não foi quebrado por essas recuperações da Itália.

Por outro lado, a selecção Espanhola inicia $36,4 \%$ das situações de finalização através da reposição lateral, enquanto a Itália inicia essas situações com mais frequência após desarme [42,9\%]. Podemos concluir que quando a Itália inicia o ataque através de desarme existe mais probabilidade de culminar a PB com finalização, do que se o fizer através de intercepção. Em relação à Espanha, a capacidade de exploração das reposições laterais será um aspecto determinante neste jogo, uma vez que é a acção mais utilizada para iniciar a PB com e sem finalização.

\section{Eficiência da Finalização}

As duas equipas apresentam o mesmo número total de remates (17). Contudo, a Itália tem maior número de remates enquadrados (10), do que a Espanha (6), ao que corresponde também um maior número de PBCF (14) para a Itália, comparativamente às 11 da Espanha. Como vimos através do Coeficiente de Produção Ofensiva (ver 4.1), a Itália apresenta uma melhor utilização da PB. De forma a avaliar a eficiência das acções de finalização propomos o Coeficiente de Eficiência da Finalização (CEF), que relaciona o número de remates enquadrados (RE) com o número de PBCF, expresso pela seguinte equação: [CEF = RE / PBCF * 100].
Assim, para a selecção Espanhola temos, CEF = 6/11 *100 = 54,5\%; para a selecção Italiana temos, CEF $=10 / 14 * 100=71,4 \%$.

A Itália, para além de ter maior percentagem de PBCF, de acordo com o CEF tem, também, maior percentagem de remates enquadrados.

\section{CONCLUSÕES}

De acordo com os indicadores propostos, o CPO e o CEF, a Itália estará a ser a equipa mais eficiente no jogo, uma vez que tem alcançado a fase de finalização e tem enquadrado os remates mais vezes. Contudo, o resultado final estará sempre condicionado pela eficácia da finalização das equipas.

A imprevisibilidade do jogo não permite recolher dados sobre a eficácia da finalização antes de acontecerem os golos. Por outro lado, estes indicadores da eficiência do processo ofensivo não dependem da imprevisibilidade da existência do golo. Assim, parece-nos pertinente a sua utilização com vista à compreensão dos processos de jogo da equipa.

No entanto, são necessários estudos que comprovem a utilidade da informação que estes coeficientes possam transmitir às equipas técnicas. Se tal se vier a confirmar, o futuro poderá passar pela disponibilização destes dados ao treinador durante o jogo.

\section{CORRESPONDÊNCIA}

Ricardo Filipe Lima Duarte

Estação - Aborim

4750-021 Barcelos

E-mail: ricarduarte@gmail.com 


\section{REFERÊNCIAS}

1. Ferreira $P$ (2000). Caracterização da finalização em equipas de Futsal. Monografia de Licenciatura. Porto: FCDEF-UP.

2. Garcia GA (2004). Caracterización de los esfuerzos en el fútbol sala basado en el estúdio cinemático y fisiológico de la competición. Revista Digital 77. [On line]: http://www.efdeportes.com 3. Garganta J (1998). Analisar o Jogo nos Jogos Desportivos Colectivos: Uma Preocupação Comum ao Treinador e ao Investigador. Revista Horizonte, 83, 7-14.

4. Guerreiro J (2005). Caracterização da fase ofensiva e defensiva em competições de futsal: Interface entre a análise do jogo e a análise de tempo e movimento. Tese de Mestrado. Vila Real: UTAD.
5. Oliveira LM (1999). Perfil de actividade do jovem jogador de Futsal. Dissertação apresentada com vista à obtenção do grau de Mestre em Ciências do Desporto. Porto: FCDEF-UP.

6. Salgado B (2004). Caracterização da intensidade do esforço no treino e no jogo de futsal. Monografia de Licenciatura. Vila Real: UTAD.

7. Sampaio AJ \& Janeira MA (2001). Uma caminhada metodológica na rota das estatísticas e da análise do jogo de Basquetebol. Revista Digital 39. [On line]: http://www.efdeportes.com

8. Turcoliver D (1991). New Measurements Techniques and a Binomial Model of the Game of Basketball. Journal of Basketball Studies. Web: http://www.tsoft.com/ deano/

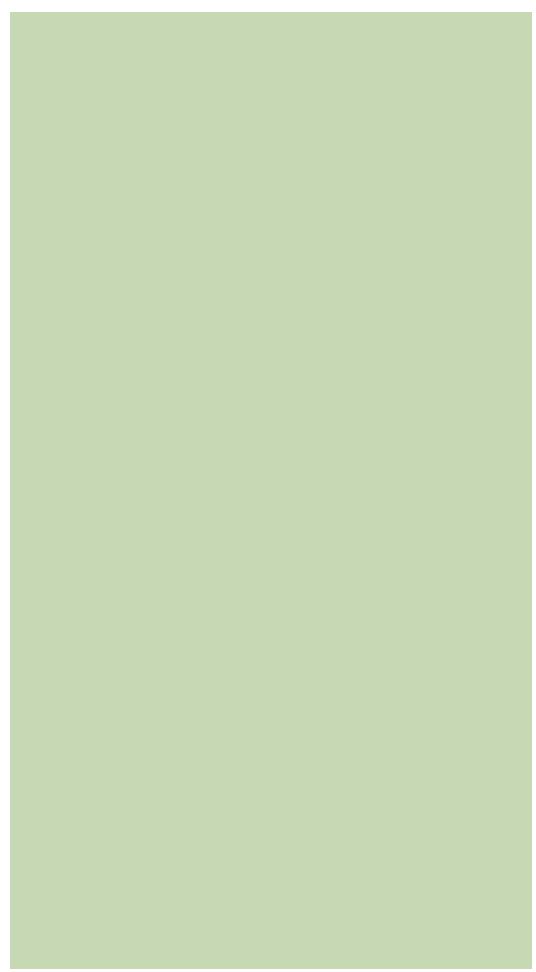

